\title{
НОРМАТИВНЫЕ ОСНОВЫ ИНТЕГРАЦИИ И СОЦИОКУЛЬТУРНОЙ АДАПТАЦИИ ДЕТЕЙ МИГРАНТОВ В СТРАНАХ ЕВРОПЫ И РОССИИ
}

Аннотация: В данной статье рассматриваются вопросы языковой и социокультурной интеграции детей мигрантов в Российской Федерации. В настоящее время языковая интеграция как взросльх мигрантов, так и их детей является одной из наиболее актуальных проблем в как в научных кругах, так и политических дебатах. В основе проведенного исследования лежат результаты анализа зарубежных и отечественных публикаций, посвященных проблемам интеграции и адаптации детей мигрантов, нормативно-правовых актов Российской Федерации, а такље подзаконных актов органов государственной власти Российской Федеращии. Проведен анализ существующих определений понятия «ребенок-мигрант», а также представлена классификация различных групп детей мигрантов. Выявлены ключевые проблемы, присущие современной российской системе интеграции детей мигрантов в принимающее общество. По результатам обзора официальных документов европейских стран, посвященных проблеме интеграции детейлигрантов, представлена эволючия подходов различных европейских государств крешению проблем сочиокультурной адаптации. В результате исследования выявлено несколько современных общепринятых подходов к интеграции детеймигрантов в странах Европы, а также обозначены возможные пути реализации данных подходов сучетом проблем и особенностей текущей системы интеграчии детей мигрантов в России.

Ключевые слова: Дети мигрантов, языковая интеграџия, образовательная интеграџия, сочиокультурная адаптация, законодательство Российской Федерачии, законодательство стран Европь, языловаяполитика, русский какиностранный, икольный язык, Совет Европь .

Abstract: This article examines the questions of the language and sociocultural integration of the migrants' children in the Russian Federation. Currently, the time of the language integration among adult migrants and their children is one of the most relevant issues within the scientific circles, as well as political debates. This research is based on results of the analysis of foreign and Russian publication, dedicated to the problems of integration and adaptation of the migrants' children, normative legal acts of the Russian Federation, and bylaws of the government of the Russian Federation. The author conducts an analysis of the existing definitions of the notion of "migrant child", as well as presents classification of the various groups of the migrants' children. The key issues inherent to the modern Russian system of integration of the migrants' children into the accepting society are being determined. In accordance with the results of review of the official documents of the European countries on the problem of integration of the migrants' children, the article demonstrates an evolution of approaches of various European states towards the solution of the problem of sociocultural adjustment. In conclusion, the author highlights several modern generally accepted approaches towards integration of the migrants' children in the countries of Europe, as well as signifies the possible ways of implementation of such approaches, considering the nuances and peculiarities of the current system of integration of the migrants' children in Russia.

Keywords: Language policy, European legislation, legislation of the Russian Federation, sociocultural adjustment, educational integration, language integration, children of migrants, Russian as a foreign language, school language, Council of Europe.

а сегодняшний день вопросы языковой и социокультурной интеграции мигрантов и их детей являются предметом политических дебатов и законодательных инициатив во многих странах Европы и мира. Не исключением является и Российская Федерация. В настоящее время сфера языковой и социокультурной интеграции взрослых мигрантов развивается достаточно активно. В 2014 году Федеральным законом «О внесении изменений в Федеральный закон «О правовом положении иностранных граждан в Российской Федерации» [1] в Федеральный закон от 25 июля 2002 г. № 115-Ф3 «О правовом положении иностранных граждан в Российской Федерации» была введена статья 15.1 «Подтверждение иностранными гражданами владения русским языком, знания истории России и основ законодательства Российской Федерации». Согласно данной статье, иностранный гражданин при обращении за получением разрешения на временное проживание, вида на жительство, разрешения на работу либо патента обязан подтвердить владение русским языком, знание истории России и основ законодательства Российской Федерации одним из следующих документов: 1) сертификатом о владении русским языком, знании истории России и основ законодательства Российской Федерации; 2) документом государственного образца об образовании (на уровне не ниже основного общего образования), выданным образовательным учреждением на территории государства, входившего в состав СССР до 1 сентября 1991 г.; 3) документом об образовании и (или) о квалификации, 


\section{Право и политика $11(203) \cdot 2016$}

выданным лицам, успешно прошедшим государственную итоговую аттестацию на территории Российской Федерации с 1 сентября 1991 г.

На текущий момент вопросы языковой и социокультурной интеграции детей мигрантов как в России, так и за рубежом затронуты в меньшей степени. При рассмотрении положения детей мигрантов на территории того или иного государства возникает ряд типовых проблем.

В научной литературе отсутствует единое определение понятия «мигрант», а также единый принцип определения миграционного статуса ребенка. Так, согласно исследованию ОЭСР (Организация экономического сотрудничества и развития, Organisation for Economic Co-operation and Development, OECD) 2010 года, дети-мигранты первого поколения - это дети двух иностранных граждан, родившиеся за пределами территории принимающей страны; дети-мигранты второго поколения - это дети двух иностранных граждан, родившиеся на территории принимающей страны [2]. В то же время, исследования Совета Европы [3] рассматривают в качестве детей-мигрантов только несовершеннолетних беженцев. В отечественной научной литературе вопрос определения понятий «мигрант» и «ребенок-мигрант» также является достаточно острым. Так, И.С. Сапрыкин [4] выявил в своем исследовании различные трактовки термина «мигрант», встречающиеся в современных российских исследованиях. А.А. Рыбаковский определяет мигранта как «лицо, совершающее миграцию, т.е. пересекающее границы тех или иных территорий со сменой постоянного места жительства навсегда или на более или менее длительное время» [5]. Согласно В.С. Малахову [6], иммигранты - это «иностранные граждане, более года проживающие на территории определенного государства». Классификация мигрантов на мигрантов первого, второго и третьего поколений (см. статьи В.С. Малахова, В.И. Мукомеля [7]) также размывает границы данного термина.

Проблема отсутствия единого определения детей мигрантов выражается в ряде таких проблем, как отсутствие достоверной и актуальной статистической информации о количестве прибывших на территорию Российской Федерации, а также проживающих в России мигрантов и их детей. Функции по сбору сведений о количестве иностранных граждан и лиц без гражданства осуществляют различные органы государственной власти (Главное управление по вопросам миграции Министерства внутренних дел РФ - ГУВМ МВД (ранее - ФМС России, упраздненная в 2016 году [8]), Прокуратура РФ, органы исполнительной власти субъектов РФ), образовательные учреждения (школы, вузы, учреждения среднего специального образования).
Вышеперечисленные организации занимаются сбором сведений о миграционной ситуации для своих внутренних целей, в связи с чем они определяют понятия «мигрант» и «ребенок-мигрант» по-разному. В результате, сравнение собираемых данными организациями статистических сведений представляется практически невозможным из-за применения ими различных оснований учета. Несогласованность статистики приводит к ситуации, когда по информации из различных источников от 5 до 50 процентов школьников Санкт-Петербурга являются выходцами из семей мигрантов [9].

Ещё одна важная проблема - несовершенство законодательной базы, определяющей права детей мигрантов. Данная проблема затрагивалась в статьях А.И. Борновицкой [10], Е.В. Гурченкова [11], исследовании «Положение детей мигрантов в СанктПетербурге» [9] как фактор, затрудняющий интеграцию и адаптацию детей мигрантов. Тем не менее, за последние два года миграционное законодательство Российской Федерации подверглось существенным изменениям. Таким образом, существует необходимость актуализации информации, представленной в работах российских авторов.

Так, согласно Федеральному закону от 25 июля 2002 г. № 115-Ф3 «О правовом положении иностранных граждан в Российской Федерации» [12], в Российской Федерации «миграционной судьбе» родителей следуют члены семей высококвалифицированных специалистов, а также члены семей трудовых мигрантов, прибывших из стран-членов Евразийского экономического союза. В отношении членов семей (детей) иных иностранных граждан соответствующие нормы отсутствуют. В результате, члены семей прочих мигрантов зачастую вынуждены покидать территорию Российской Федерации и затем снова возвращаться в Россию каждые 90 дней, что негативно сказывается на адаптации и интеграции детей иностранных граждан в российское общество, нарушает непрерывность учебного процесса. На текущий момент правоприменительная практика пытается сгладить недостатки федерального законодательства и продлевает срок пребывания детей мигрантов на срок патента их родителей. Согласно находящемуся в открытом доступе ответу Департамента по организации работы с иностранными гражданами ФМС России от 29 апреля 2014 г. № МС-5/3-29515 «О рассмотрении обращения» [13], «территориальным органам ФМС России рекомендовано, в случае обращения иностранных граждан или принимающей стороны, продлевать срок пребывания членам семьи иностранного гражданина, прибывшего в Российскую Федерацию в порядке, не требующем получения визы, 
и получившего разрешение на работу или патент - на срок действия соответствующих разрешительных документов». При этом ФМС (в настоящий момент - ГУВМ МВД) ссылается на ст. 5 Федерального закона № 115-Ф3 «О правовом положении иностранных граждан в Российской Федерации», согласно которой срок временного пребывания иностранного гражданина в Российской Федерации может быть продлен, если изменились условия или перестали существовать обстоятельства, в связи с которыми ему был разрешен въезд в Российскую Федерацию.

В связи с этим представляется, что формулировка ст. 5 п. 3 Федерального закона «О правовом положении иностранных граждан на территории Российской Федерации» является одним из примеров необоснованно широких пределов усмотрения для органов государственной власти. Согласно тексту ст. 3 Методики проведения антикоррупционной экспертизы нормативных правовых актов и проектов нормативных правовых актов, утверждённой Постановлением Правительства Российской Федерации от 26 февраля 2010 г. № 96 «Об антикоррупционной экспертизе нормативных правовых актов и проектов нормативных правовых актов» [14], широта дискреционных полномочий, а именно «отсутствие или неопределенность сроков, условий или оснований принятия решения» органами государственной власти, является необоснованно широкими пределами усмотрения, а следовательно, коррупциогенным фактором. Более того, отсутствие в федеральном законодательстве прямо закрепленной обязанности органов государственной власти продлевать срок пребывания детей иностранных трудящихся на территории Российской Федерации уже оказало негативное влияние на интеграцию детей мигрантов в российское общество. Так, в исследовании «Положение детей мигрантов в Санкт-Петербурге» упоминается, что «если родители-иностранцы не имеют возможности каждые 90 дней вывозить ребенка за пределы РФ и ввозить его обратно, ребенок оказывается нелегальным мигрантом, даже если у его родителей есть легальное разрешение на работу и действующая временная регистрация» [9]. В связи с этим представляется целесообразным внести изменения в федеральное законодательство и прямо закрепить права детей мигрантов на пребывание на территории Российской Федерации на срок наличия соответствующих разрешительных документов у их родителей. Подобная законодательная новелла позволит исключить излишнюю дискрецию, предоставляемую органам ГУВМ МВД (ранее - ФМС России) при решении вопросов о продлении срока пребывания ребенкамигранта на территории РФ, что будет способствовать интеграции детей мигрантов в принимающее общество, а также минимизирует влияние коррупциогенных факторов на деятельность органов государственной власти (дискреционные полномочия).

Однако одной из главных проблем образования детей мигрантов является проблема языковой интеграции. Язык играет ключевую роль в освоении школьной программы. В соответствии с проектом Федерального закона «О социальной и культурной адаптации и интеграции иностранных граждан в Российской Федерации» [15], «основой социальной и культурной адаптации и интеграции иностранных граждан является уважение к государственному языку». Также Совет Европы в своих резолюциях неоднократно отмечал, что «язык - это инструмент приобретения знаний, один из важных атрибутов развития личности, средство и фактор понимания реальности, источник творческих способностей» [16]. С языка начинается интеграция человека в социокультурную среду, знакомство с обществом принимающей страны.

Проблема языковой и образовательной интеграции детей и подростков из семей мигрантов достаточно серьезно проработана на Европейском уровне. В 1996 году были предприняты действия, прямо направленные на языковую интеграцию не только мигрантов, но и членов их семей. Так, ст. 19 п. 11 Европейской социальной хартии устанавливает обязанность стран, её ратифицирующих, «поощрять обучение и оказывать содействие в обучении работников-мигрантов и членов их семей национальному языку принимающего государства или, если таких языков несколько, одному из них» [17]. Российской Федерацией, несмотря на ратификацию 64 положений данного документа, упомянутый пункт не ратифицирован [18]. Из 50 стран, ратифицировавших данную хартию, только 16 ратифицировали указанный пункт [19].

После третьего саммита глав стран и государств Совета Европы, состоявшегося в Варшаве в мае 2005 года, в котором приняли участие 46 стран-участниц, было принято решение о запуске специальной программы «Языки в образовании / Языки для образования» [20], направленной на развитие политики в области языковой интеграции детей мигрантов. В рамках деятельности данного проекта было проведено несколько конференций, разработана так называемая «Белая книга о межкультурном диалоге» [21] (документ, поясняющий политику стран-участниц Совета Европы), где были определены понятия социальной сплоченности и межкультурного диалога, утверждена центральная роль языков в процессе образования, изложены различные предложения в области совершенствования 


\section{Право и политика $11(203) \cdot 2016$}

школьного образования, в частности, развитие межкультурных направлений в программах курсов школьных предметов.

Завершением проекта «Языки в образовании / Языки для образования» стал форум «Права учащихся на получение качественного образования - роль языковых и межкультурных компетенций», проведенный в Женеве в ноябре 2010 года. Основные итоги и положения проекта были изложены в документе «Лингвистическая и образовательная интеграция детей и подростков из семей мигрантов» [18].

Департамент языковой политики Совета Европы в своих исследованиях выделяет три основных уровня лингвистической интеграции [22]:

1) Слабая языковая интеграция: имеющиеся языковые ресурсы неравномерно распределены в языковом репертуаре человека, потому что уровня владения языком недостаточно для лёгкого и быстрого решения коммуникативных задач. Процесс коммуникации чаще всего требует вмешательства третьих лиц, и его успех зависит в большей степени от стремления к познанию чужого языка и положительного отношения к нему у других мигрантов.

2) Функциональная языковая интеграция: языковых ресурсов достаточно для успешной коммуникации в различных социальных, профессиональных и личных ситуациях. Такой уровень владения языком подразумевает, что большинство речевых актов будут успешными. В речи мигрантов могут возникать ошибки или примеры фоссилизации, которые мигранты не будут замечать, если они больше заинтересованы в эффективности общения, чем в соблюдении правил нового языка. росткам. Однако в процессе интеграции в образовательный процесс последние сталкиваются с дополнительными трудностями. Согласно исследованиям подразделения языковой политики Совета Европы, школьный язык можно разделить на два типа [23]:

1) Разговорный язык (или язык диалога, также называемый в литературе языком интерактивного взаимодействия) - язык неформального общения. Используя его, человек делится с окружающими информацией по бытовым вопросам в неофициальной обстановке.

2) Академический (учебный) язык - язык школьных занятий, научных и учебных текстов. Компетенции в академическом языке являются необходимым условием для успешного обучения и освоения школьной программы.

Для различных групп детей мигрантов уровень знаний, скорость овладения и использование данных типов школьного языка может существенно различаться. Например, дети мигрантов, прибывающие в принимающую страну в школьном возрасте, чаще всего обладают лишь базовыми навыками в разговорном языке, в то время как их сверстники, прибывшие в принимающую страну еще в дошкольном возрасте или родившиеся в ней, могут обладать достаточными компетенциями в разговорном языке и сталкиваться с определенными трудностями овладения академическим языком (подробнее см. Таблицу 1). При организации системы языковой и образовательной интеграции детей мигрантов необходимо учитывать данные особенности.

Таблица 1 - Языковая интеграция детей мигрантов

\begin{tabular}{|l|c|c|}
\hline Дети мигрантов & Тип языка & разговорный язык \\
\hline прибывшие в дошкольном возрасте & Достаточные компетенции & Базовый уровень \\
\hline прибывшие в школьном возрасте & Базовый уровень & Отсутствие компетенций \\
\hline
\end{tabular}

3) Полная языковая интеграция: мигранты активно перестраивают свой языковой репертуар и овладевают языком принимающей страны, который впоследствии занимает место на одном уровне с уже известными им языками. У мигрантов практически отсутствуют проблемы с общением и языком, они без труда его используют, с легкостью переходя с одного языка на другой в зависимости от ситуации.

Данные уровни интеграции применимы как ко взрослым мигрантам, так и к детям и под-
В соответствии с программным документом департамента языковой политики Совета Европы «Лингвистическая и образовательная интеграция детей и подростков из семей мигрантов» [18] выделяются три пути организации системы языковой интеграции в общеобразовательных учреждениях:

1. Полное исключение детей мигрантов из общего потока учащихся. Одной из стран, выбравших данный путь организации и поддержки детей мигрантов, является Норвегия. В соответствии 
с актом Министерства образования и исследований Королевства Норвегия от 17 июля 1998 г. «О начальном и среднем образовании» [24], «учащиеся, чей родной язык отличен от норвежского или саамского, обязаны пройти специальное обучение норвежскому языку до достижения уровня знания языка, необходимого для освоения стандартной школьной программы». При необходимости учащиеся также имеют право обучаться родному языку либо проходить двуязычную программу. Учебный курс норвежского языка не зависит от возраста и знаний ученика по другим предметам. Перед началом курса для каждого учащегося определяется его уровень владения норвежским языком. Обучение по стандартной школьной программе возможно только после получения необходимых компетенций владения норвежским языком.

2. Частичное исключение из общего потока. Данный подход реализован в республике Ирландия. В соответствии с актом Министерства образования и науки Ирландии от 1998 года [25] учащиеся, чей родной язык отличен от английского или ирландского, распределяются в классы со стандартной школьной программой согласно их возрасту. Учащимся в обязательном порядке предоставляется двухгодичный курс английского языка с отрывом от обучения [26]. Максимальное количество отдельных занятий сводится к одному уроку английского языка в день в начальной школе и нескольким урокам в неделю в старших классах.

3. Полное погружение в общий поток без систематической языковой поддержки. Данный подход распространен в странах Организации экономического сотрудничества и развития [27]. Недостаток данного организационного подхода заключается в том, что он не в состоянии в полной мере предоставить учащимся возможность овладеть школьным языком как вторым языком [28].

Все три подхода можно комбинировать в зависимости от текущей ситуации и реалий той или иной принимающей мигрантов страны. Однако ключевым положением в языковой и образовательной интеграции детей мигрантов в школах является акцентирование важности языка на каждом школьном предмете в процессе обучения. Без активного участия учителей и преподавателей, уделяющих дополнительное внимание языковым аспектам изучения школьных дисциплин, полноценная языковая интеграция учащихся крайне трудна и маловероятна при любом из вышеизложенных подходов.
Для организации успешного процесса языковой и образовательной интеграции детей мигрантов необходимо обладать инструментами оценки их компетенций как в разговорном, так и в академическом языке. В этой связи специалистами Санкт-Петербургского государственного университета были разработаны новые виды тестирования: тестирование для оценки коммуникативных навыков детей-билингвов дошкольного и младшего школьного возрастов, а также тестирование по русскому языку как иностранному в сфере повседневного общения для школьников. Последний вид тестирования имеет 4 уровня по шкале общеевропейских языковых компетенций - от А1 до В2. Данные виды тестирования были специально созданы для проверки как разговорного, так и академического языка в школьной среде. Разработанные СПбГУ тесты не только проверяют уровень владения русским языком детей мигрантов, но и готовят их к сдаче «взрослого» государственного тестирования по русскому языку как иностранному языку (ТРКИ).

Таким образом, в результате проведенного анализа текущей ситуации в сфере языковой и социокультурной интеграции детей мигрантов в российское общество можно сделать вывод о том, что на сегодняшний день в Российской Федерации отсутствует единый подход к интеграции и адаптации детей мигрантов. Более того, существует острая необходимость проведения всероссийского комплексного исследования условий и уровня интеграции детей иностранных граждан в российское общество, учитывающего все аспекты адаптации и интеграции, с привлечением специалистов различных профилей (юристов, филологов, психологов и др.). 27 июня 2016 г. на заседании Совета по русскому языку при Правительстве Российской Федерации, возглавляемого Ольгой Юрьевной Голодец [29], был поставлен вопрос о необходимости проведения подобного исследования ввиду высокой актуальности и остроты проблемы интеграции и социокультурной адаптации детей мигрантов. Представляется, что только на основе комплексных научно обоснованных исследований можно принимать грамотные управленческие решения государственного масштаба, учитывающие динамику и перспективы развития тех или иных социальных процессов, в частности, принятие единой стратегии интеграции и адаптации детей мигрантов в российское общество с учетом европейского опыта и имеющихся путей интеграции и организации системы образования, описанных выше. Составление плана конкретных мероприятий, реализуемых в рамках данной стратегии, с указанием исполните- 
лей и сроков реализации отдельных пунктов плана позволит достичь целей, установленных в разработанной стратегии развития.

Помимо разработки долгосрочной стратегии развития необходимо обратить внимание на внесение изменений в действующее законодательство в сфере интеграции детей мигрантов. Так, предложенные в данной работе законодательные новеллы позволят не только ускорить интеграцию детей иностранных трудящихся, но и исключить коррупциогенные факторы из условий деятельности органов государственной власти.

\section{Библиография:}

1. О внесении изменений в Федеральный закон «О правовом положении иностранных граждан в Российской Федерации» [Электронный ресурс] : федер. закон от 20 апр. 2014 г. № 74-Ф3 // Собр. законодательства Рос. Федерации. - 2014. - № 16. - Ст. 1831. - (в ред. от 24 нояб. 2014 г.). - СПС «Консультант Плюс».

2. CO3.6: Percentage of immigrant children and their educational outcomes [Electronic Resource] / Organisation for Economic Co-operation and Development. - 2016. - Режим доступа : https://www.oecd.org/els/soc/49295179.pdf.

3. Compilation of data, situation and media reports on children in migration [Electronic Resource] / European Commission website. -2016. - Режим доступа : http:// ec.europa.eu/justice/fundamental-rights/files/rights_child/data_children_in_migration.pdf.

4. Сапрыкин И.С. Основные проблемы интеграции детей мигрантов в российском обществе и методы их решения / И.С. Сапрыкин // Актуальные вопросы современной науки и образования : Материалы III Международной научнопрактической конференции. Сборник научных трудов. НОУ «Вектор науки»; науч. ред. Г.Ф. Гребенщиков, Таганрог, 30 июня 2016 г. - М. : Изд-во «Перо», 2016. - С. 23-29.

5. Демографический понятийный словарь / В.Н. Архангельский [и др.] ; под ред. Л.Л. Рыбаковского ; М-во труда и соц. развития Рос. Федерации. Рос. акад. наук. Ин-т соц. - полит. исслед. - М. : Изд-во Центр соц. прогнозирования, 2003. $-352 \mathrm{c}$.

6. Малахов В.С. Интеграция мигрантов: европейский опыт и перспективы России: рабочая тетрадь / В.С. Малахов // Российский совет по междунар. делам / под ред. И.С. Иванова. - М.: Спецкнига, 2014. - 24 с.

7. Мукомель В.И. Политика интеграции мигрантов в России: вызовы, потенциал, риски: рабочая тетрадь / В.И. Мукомель // Российский совет по междунар. делам / под ред. И.С. Иванова. - М.: Спецкнига, 2013. - 34 с.

8. О совершенствовании государственного управления в сфере контроля за оборотом наркотических средств, психотропных веществ и их прекурсоров и в сфере миграции [Электронный ресурс] : указ Президента РФ от 05 апр. 2016 г. № 156 // Собр. Законодательства Рос. Федерации. - 11 апр. 2016 г. - № 15. - Ст. 2071. - СПС «Консультант Плюс».

9. Положение детей мигрантов в Санкт-Петербурге / Д.А. Александров [и др.] : Научно-учебная лаборатория «Социология образования и науки» Федерального государственного автономного образовательного учреждения высшего профессионального образования «Национальный исследовательский университет «Высшая школа экономики». - М. : Детский фонд ООН (ЮНИСЕФ), 2012. - 168 с.

10. Борновицкая А.И. Нарушение прав детей беженцев, мигрантов и внутриперемещённых лиц / А.И. Борновицкая // Конституционализм и государствоведение. - 2011. - № 5. - С. 162-167.

11. Гурченков Е.В. Роль языка в интеграции детей мигрантов в московское общество / Е.В. Гурченков // Социологические исследования. - 2010. - № 4. - С. 134-137.

12. О правовом положении иностранных граждан в Российской Федерации [Электронный ресурс] : федер. Закон от 25 июля 2002 г. № 115-ФЗ // Собр. Законодательства Рос. Федерации. - 29 июля 2002 г. - № 30 - Ст. 3032 . - (в ред. от 03 июля 2016 г.). - СПС «Консультант Плюс».

13. О рассмотрении обращения [Электронный ресурс] : ответ департамента по организации работы с иностранными гражданами управления по организации разрешительно-визовой работы (УОРВР) Федеральной Миграционной службы (ФМС России) от 29 апр. 2014 г. № MC - 5/3 - 29515 // TIM Group. - 2016. - Режим доступа : http://www.timservices.ru/ ru/novosti/128-pozitsiya-fms-rossii-po-voprosu-prodleniya-sroka-vremennogo-prebyvaniya-soprovozhdayushchim-chlenamsemi-inostrannykh-rabotnikov-v-ezzhayushchikh-v-bezvizovom-poryadke.html.

14. Об антикоррупционной экспертизе нормативных правовых актов и проектов нормативных правовых актов [Электронный ресурс] : постановление Правительства Российской Федерации от 26 февраля 2010 г. № 96 // Собр. Законодательства Рос. Федерации. - 8 марта 2010 г. - № 10. - Ст. 1084. - (в ред. от 18 июля 2015 г.) . - СПС «Консультант Плюс».

15. О социальной и культурной адаптации и интеграции иностранных граждан в Российской Федерации [Электронный pecypc] : проект федер. закона // Спав. - правовая система «Консультант Плюс». - 2016. - Режим доступа : http://www. consultant.ru/cons/cgi/online.cgi?req=doc\&base=PRJ\&n=116341.

16. The linguistic and educational integration of children and adolescents from migrant backgrounds [Electronic Resource] : Concept Paper / prep. by David Little // Council of Europe : [web-site]. - Режим доступа : https:/www.coe.int/t/dg4/linguistic/ Source/Source2010_ForumGeneva/MigrantChildrenConceptPaper_EN.pdf.

17. Европейская социальная хартия (пересмотренная) (принята в г. Страсбурге 3 мая 1996 г.) [Электронный ресурс] : официальный перевод на русский язык // Бюллетень международных договоров. - 2010. - № 4. - Ст. 17-67. - СПС «Консультант Плюс».

18. О ратификации Европейской социальной хартии (пересмотренной) от 3 мая 1996 года [Электронный ресурс] : федер. закон от 3 июня 2009 г. № 101-Ф3 // Собр. законодательства РФ. - 8 июня 2009 г. - № 23. - Ст. 2756. - СПС «Консультант Плюс». 
19. Signatures and ratifications of the European Social Charter, its Protocols and the European Social Charter (revised) [Electronic Resource] : Situation at 26 March 2013 // Council of Europe : [web-site]. - Режим доступа : http://www.coe.int/en/web/turineuropean-social-charter/signatures-ratifications.

20. Languages in Education Languages for Education [Electronic Resource] : A platform of resources and references for plurilingual and intercultural education // Language policy division, Council of Europe : [web-site]. - Режим доступа : http://www. coe.int/t/dg4/linguistic/Source/LE_texts_Source/platformResources_en.pdf.

21. White paper on intercultural dialogue [Electronic resource] // Council of Europe : [web-site]. - Режим доступа : http://www. coe.int/t/dg4/intercultural/whitepaper_interculturaldialogue_2_EN.asp.

22. Forms of linguistic integration [Electronic resource] : Linguistic integration of adult migrants (LIAM) // Council of Europe : [web-site]. - Режим доступа : http://www.coe.int/en/web/lang-migrants/forms-of-linguisticintegration?p_p_id=56_ INSTANCE_uinDIV4nujaf\&p_p_lifecycle $=0 \& p \_p \_s t a t e=$ normal\&p_p_mode $=$ view\&p_p_col_id $=$ column4\&p_p_col_ count $=1 \&$ 5 $\overline{6}$ INSTANCE_uinDIV4nujaf_languageId $=\mathrm{ru}$ _RU.

23. Languages of schooling [Electronic resource] : Education and Languages, Language Policy // Council of Europe : [web-site]. - Режим доступа : http://www.coe.int/t/dg4/linguistic/schoollang_EN.asp.

24. The Education Act [Electronic Resource] : Act of 17 July 1998 no. 61 relating to Primary and Secondary Education and Training (in force as of 1 August 2013) // Departementenes sikkerhets-og serviceorganisasjon (DSS) Regjeringen.no. - Режим доступа : https://www.regjeringen.no/globalassets/upload/kd/vedlegg/grunnskole/dokumenter/educationact_with_amendments_entered2013.pdf.

25. Education Act [Electronic Resource] : Act Number 51 of 1998 // Department of Education and Skills website. - Режим доступа : http://www.oireachtas.ie/documents/bills28/acts/1998/a5198.pdf.

26. Integrating non-English speaking pupils into the school and curriculum [Electronic Resource] : Handbook for primary schools // Prepared by Integrate Ireland Language and Training in collaboration with language support teachers working in primary schools throughout Ireland, 2003. - Режим доступа : http:/www.ncca.ie/uploadedfiles/Curriculum/inclusion/ Handbook_primary.pdf.

27. Where immigrant students succeed [Electronic Resource] : A comparative review of performance and engagement in PISA 2003 // Organisation for Economic Co-operation and Development. - 2006. - Режим доступа : http://www.oecd.org/edu/school/ programmeforinternationalstudentassessmentpisa/whereimmigrantstudentssucceed-acomparativereviewofperformanceandengagementinpisa2003.htm.

28. Gogolin I. Streitfall Zweisprachigkeit The bilingualism controversy / I. Gogolin, U. Neumann, [Hrsg.]. - VS Verlag für Sozialwissenschaften. - Wiesbaden : GWV Fachverlage GmbH, 2009. - P. 338.

29. Ольга Голодец провела заседание Совета по русскому языку [Электронный ресурс] // Правительство Российской Федерации. - 27 июня 2016. - Режим доступа : http://government.ru/news/23513/.

\section{References (transliterated):}

1. Saprykin I.S. Osnovnye problemy integratsii detei migrantov v rossiiskom obshchestve i metody ikh resheniya / I.S. Saprykin // Aktual'nye voprosy sovremennoi nauki i obrazovaniya : Materialy III Mezhdunarodnoi nauchno-prakticheskoi konferentsii. Sbornik nauchnykh trudov. NOU «Vektor nauki»; nauch. red. G.F. Grebenshchikov, Taganrog, 30 iyunya 2016 g. - M. : Izdvo «Pero», 2016. - S. 23-29.

2. Malakhov V.S. Integratsiya migrantov: evropeiskii opyt i perspektivy Rossii: rabochaya tetrad' / V.S. Malakhov // Rossiiskii sovet po mezhdunar. delam / pod red. I.S. Ivanova. - M.: Spetskniga, 2014. - 24 s.

3. Mukomel' V.I. Politika integratsii migrantov v Rossii: vyzovy, potentsial, riski: rabochaya tetrad' / V.I. Mukomel' // Rossiiskii sovet po mezhdunar. delam / pod red. I.S. Ivanova. - M.: Spetskniga, 2013. - 34 s.

4. Bornovitskaya A.I. Narushenie prav detei bezhentsev, migrantov i vnutriperemeshchennykh lits / A.I. Bornovitskaya // Konstitutsionalizm i gosudarstvovedenie. - 2011. - № 5. - S. 162-167.

5. Gurchenkov E.V. Rol' yazyka v integratsii detei migrantov v moskovskoe obshchestvo / E.V. Gurchenkov // Sotsiologicheskie issledovaniya. - 2010. - № 4. - S. 134-137.

6. Gogolin I. Streitfall Zweisprachigkeit The bilingualism controversy / I. Gogolin, U. Neumann, [Hrsg.]. - VS Verlag für Sozialwissenschaften. - Wiesbaden : GWV Fachverlage GmbH, 2009. - P. 338. 